\title{
KEBERSIHAN DIRI MELALUI PROGRAM CUCI TANGAN SEBAGAI BENTUK KESADARAN SISWA HIDUP SEHAT DI SDN INTI 11 BANJARMASIN
}

\author{
Agus Irawan ${ }^{1}$, Mey Risa ${ }^{2}$, Adi Pratomo ${ }^{3}$, Novi Shintia ${ }^{4}$ \\ Politeknik Negeri Banjarmasin 1,2,3,4 \\ agusirawan@poliban.ac.id ${ }^{1}$ \\ meyrisa@poliban.ac.id ${ }^{2}$ \\ adipratomo@poliban.ac.id ${ }^{3}$ \\ novishintia@yahoo.co.id ${ }^{4}$
}

\begin{abstract}
PPM's community service activities are carried out as a multi-disciplinary scientific application, namely environmental health and hygiene education activities. The proposed scheme is the Community Empowerment Program scheme.

This service activity is problem solving, which is in the form of education and application of healthy life by getting students to cultivate hand washing to improve the quality of personal health both at school, at home and in the student environment. This activity is directed in the form of the installation of water taps, counseling, proper hand washing practices, and the socialization of the importance of healthy living starting with getting used to washing hands before going to school.

The target audience (partner) is Banjarmasin's 11th core SDN, namely students from grades 1-6. This activity program is to increase the capacity of students to learn / get used to a healthy life in order to support school academic achievement.

Keyword: personal hygiene, hand washing, facility improvement, counseling, monitoring
\end{abstract}

\begin{abstract}
ABSTRAK
Kegiatan pengabdian kepada masyarakat PPM ini dilakukan sebagai penerapan keilmuan yang bersifatt multi disipliner, yaitu kegiatan edukasi kesehatan dan kebersihan lingkungan. Adapun skema yang diusulkan yaitu skema Program Pemberdayaan Masyarakat.

Kegiatan pengabdian ini bersifat problem solving, yaitu berupa edukasi dan penerapan hidup sehat dengan membiasakan siswa membudayakan cuci tangan guna meningkatkan kualitas kesehatan diri baik di sekolah, di rumah dan dilingkungan siswa berada. Kegiatan ini diarahkan berupa pembuatan instalasi kran air, penyuluhan, praktik cuci tangan yang benar, dan sosialisasi pentingnya hidup sehat dimulai dengan membiasakan cuci tangan sebelum beraktifitas di sekolah.

Khalayak sasaran (mitra) adalah SDN inti 11 Banjarmasin, yaitu para siswa dari kelas 1 sampai dengan kelas 6. Program kegiatan ini untuk meningkatkan kapasitas siswa agar belajar membiasakan hidup sehat agar bisa menunjang prestasi akademik sekolah.
\end{abstract}

Kata Kunci : kebersihan diri, mencuci tangan, pembenahan fasilitas, penyuluhan, pemantauan 


\section{PENDAHULUAN}

Kebersihan adalah sebagian dari Iman. Kebersihan bagian dari kesehatan. Kesehatan merupakan hal terpenting dalam kehidupan kita sehari-hari. Semua elemen masyarakat harus memperhatikan dan membudayakan hidup sehat sejak usia dini. Salah satu bagian penting dari hidup sehat adalah menjaga kebersihan diri dan lingkungan sekitar. Apalagi kebersihan diri dan lingkungan memiliki hubungan yang erat, karena terkait dengan aktifitas dan rutinitas manusia sehari-hari.

Usia dini yang dimaksud dapat dimulai dilingkungan sekolah dasar bagi siswasiswanya, seperti pada SDN Inti 11 Banjarmasin. Sekolah ini memiliki siswa yang cukup banyak dari kelas 1, 2, 3, 4, 5 dan 6. SDN Inti 11 Banjarmasin beralamat di jalan Hasan Basri gg. awang bahagia RT 18 Kelurahan Sungai Miai Kecamatan Banjarmasin Utara-Kota Banjarmasin Propinsi Kalimantan Selatan.

Upaya pemeliharaan kebersihan diri mencakup tentang kebersihan rambut, mata, telinga, gigi, mulut, kulit, kuku, serta kebersihan dalam berpakaian. Dalam upaya pemeliharaan kebersihan diri ini, pengetahuan akan pentingnya kebersihan diri tersebut sangat diperlukan. Karena pengetahuan atau kognitif merupakan domain yang sangat penting dalam membentuk tindakan seseorang (Notoatmodjo,1997).

Adapun kondisi umum yang ditemukan pada SDN 11 Inti Banjarmasin banyak kendala yang didapat seperti minimnya fasilitas cuci tangan, dan kurangnya pemahaman tentang kebersihan diri pada siswa yang berakibat siswa rentan akan penyakit tertentu (misalnya sakit perut) yang diakibatkan oleh minimnya kebiasaan cuci tangan dengan baik dan benar.

\section{TINJAUAN PUSTAKA}

Pengertian Personal hygiene (kebersihan diri) adalah tindakan memelihara kebersihan dan kesehatan seseorang untuk kesejahteraan fisik dan psikis, menurut pendapat (Tarwoto,2010). Dimana disini dijelaskan bahwa kebersihan diri merupakan ciri berperilaku hidup sehat.

Adapun mengutip dari Jurnal Pengabdian Masyarakat (Siti Juariah dkk, 2018) dijelaskan menurut (Linda, 2004) bahwa mencuci tangan merupakan proses pembuangan kotoran dan debu secara mekanis dari kedua belah tangan dengan memakai sabun dan air. Tujuan mencuci tangan adalah untuk menghilangkan kotoran dan debu secara mekanis dari permukaan kulit dan mengurangi jumlah mikroorganisme.

Kebersihan tangan sangatlah penting bagi setiap orang. Kebiasaan mencuci tangan sebelum makan harus dibiasakan. Pada umumnya ada keengganan untuk mencuci tangan sebelum mengerjakan sesuatu karena dirasakan memakan waktu, apalagi letaknya cukup jauh. Dengan kebiasaan mencuci tangan, sangat membantu dalam mencegah penularan bakteri dari tangan kepada makanan (DepkesRI, 2006) 
Masih mengutip dari Jurnal Pengabdian Masyarakat (Siti Juariah dkk, 2018) bahwa menurut (WHO, 2008) kebersihan tangan adalah ukuran utama untuk mengurangi infeksi. Ada 10 langkah yang menjadi pedoman dalam WHO untuk mensosialisasikan cuci tangan dengan sabun dan air. Cara mencuci tangan yang benar adalah sebagai berikut:

a. Cuci tangan dengan air yang mengalir dan gunakan sabun. Tidak perlu harussabun khusus antibakteri, namun lebih disarankan sabun yang berbentukcairan.

b. Gosok tangan setidakknya selama 15-20 detik.

c. Bersihkan bagian telapak tangan, punggung tangan, sela-sela jari, ibu jari,ujung jari, kuku dan pergelangan tangan.

d. Basuh tangan sampai bersih dengan air yang mengalir.

e. Keringkan dengan handuk bersih atau alat pengering lain.

f. Gunakan tisu/handuk sebagai penghalang ketika mematikan air(Atikah, 2012).

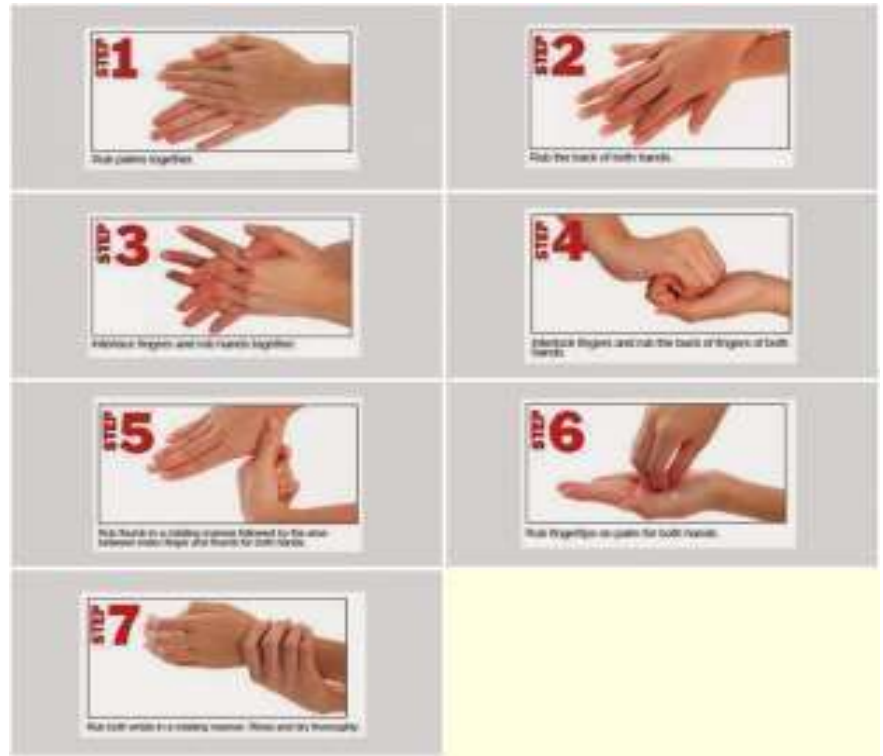

Gambar 1. Prosedur 7 langkah mencuci tangan

(Sumber: www.sditmadani.sch.id/2014/01/7-langkah-cara-mencuci-tangan-yang. html)

\section{METODE PELAKSANAAN}

Kegiatan pengabdian kepada masyarakat menggunakan metode : "Pembenahan fasilitas, Penyuluhan dan Pendampingan", yaitu :

1) Survey lapangan melihat kondisi fisik Sekolah dan prilaku siswa

2) Membeli alat dan bahan instalasi tempat pencucian tangan yang layak pakai

3) Mengerjakan alat dan bahan

4) Penyuluhan 
5) Pendampingan dengan cara memantau dan mengevaluasi perubahan prilaku siswa

6) Menilai sejauhmana peran sekolah aktif membenahi masalah kesehatan diri dan kebersihan lingkungan sekolah setelah bekerja sama dengan Tim P3M Politeknik Negeri Banjarmasin.

Jadi Hasil kegiatan pengabdian diharapkan dapat meningkatkan kesadaran siswa dan guru akan arti pentingnya kesehatan dan kebersihan diri melalui kebiasaan cuci tangan.

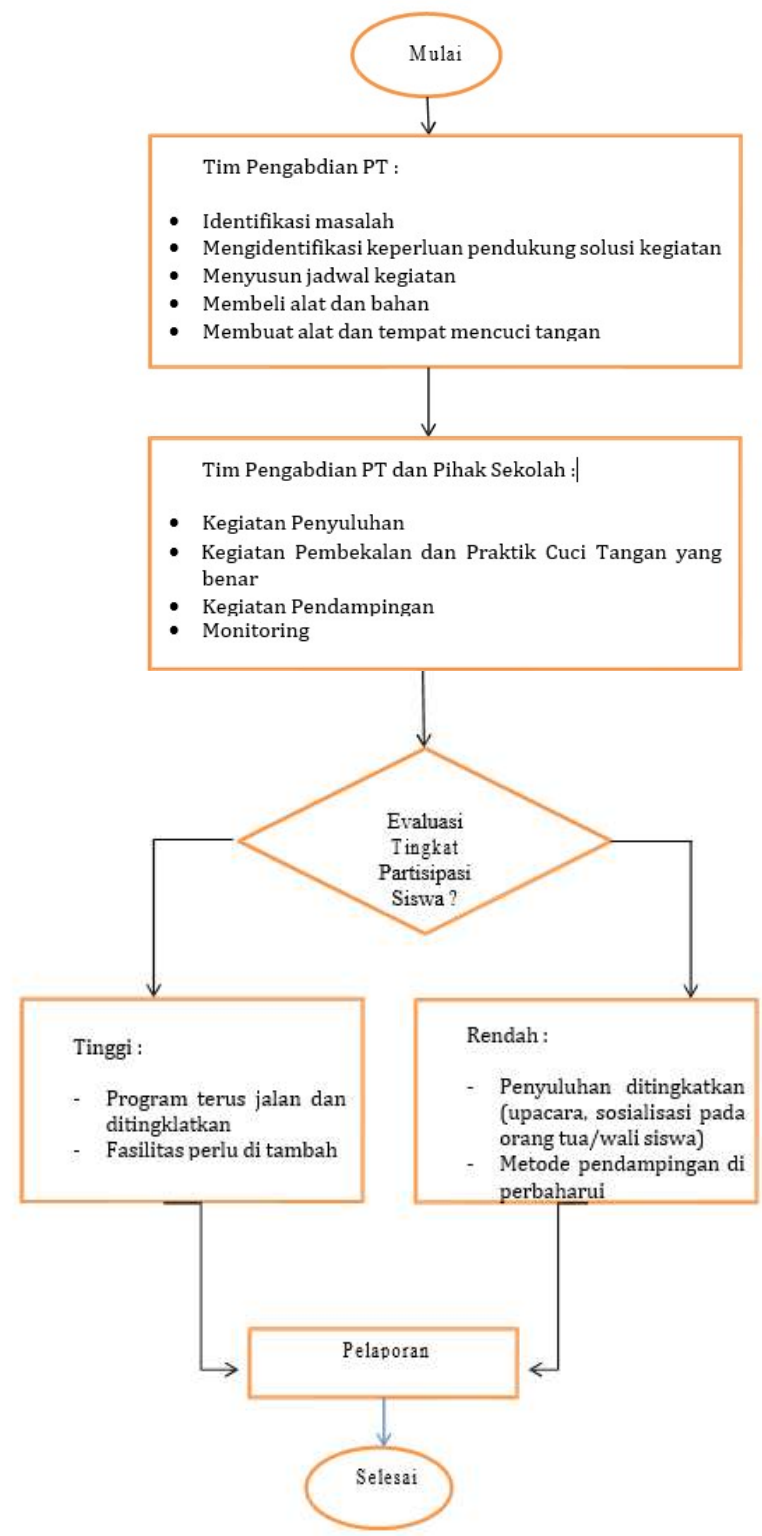

Gambar 2. Metode Pelaksanaan Kegiatan 


\section{HASIL DAN PEMBAHASAN}

Dalam Kegiatan PPM ini, tim bekerja bukan hanya penyuluhan dan pembinaan, tapi yang lebih banyak dikerjakan adalah membenahi infrastruktur yang belum ada/masih minim. Adapun untuk lebih jelasnya dapat diurutkan sebagai berikut :

1) Perbaikan dan penambahan fasilitas infrastruktur pencucian tangan

2) Penyuluhan dan pendampingan oleh tim Poliban dan juga melibatkan keaktifan guru di sekolah ini

3) Monitoring dan evaluasi berupa kunjungan rutin guna melihat aktifitas dan kemajuan pola hidup sehat dari siswa-siswa SDN Inti 11 Banjarmasin.

Kegiatan PPM Tim Poliban di SDN 11 Inti Banjarmasin sesuai dengan tujuannya di titik beratkan tercapainya target jangka pendek yaitu siswa terbiasa mencuci tangan dengan benar, pada 3 aktifitas :

- Sebelum dan sesudah istirahat

- Pada waktu setelah pelajaran praktik olah raga dan laboratorium

- Menggunakan air wudhu dengan hemat dan cermat

Adapun kegiatan PPM berikutnya untuk skema kesadaran dan kesehatan masyarakat maka akan diperkuat pada sasaran selanjutnya yaitu jangka panjang yang akan ditentukan rumusan, program dan sasarannya.

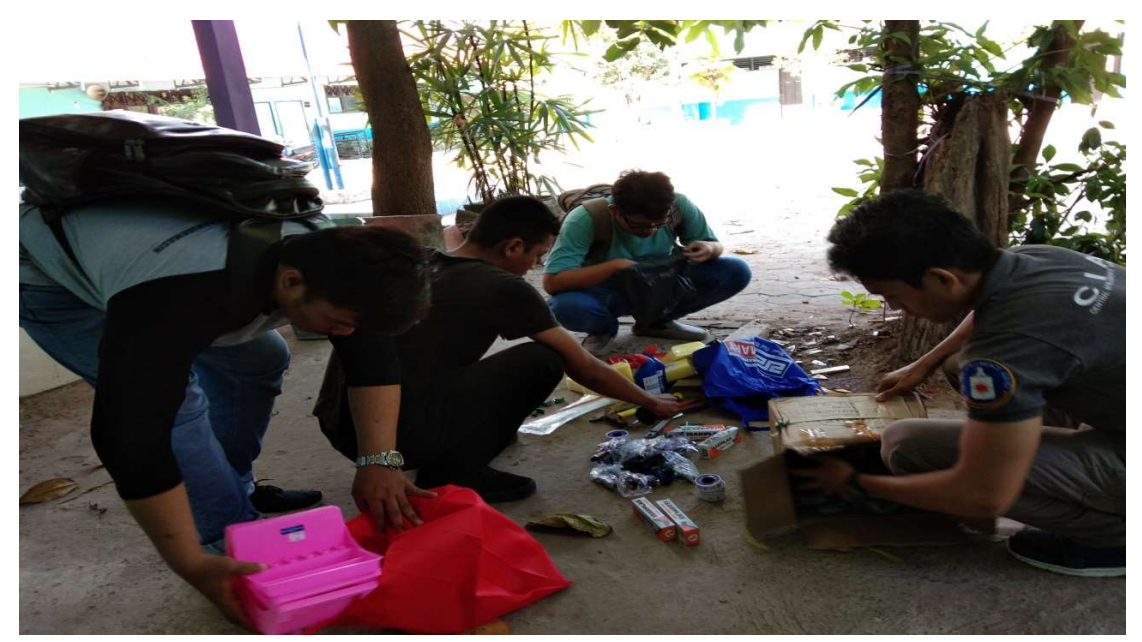

Gambar 3. Persiapan

Dalam persiapan pemasangan alat pencuci tangan di 18 titik lokasi, tim membeli alat dan bahan yang diperlukan mulai pipa, westafel, alat bangunan pendukung, dan lain-lain. Kegiatan ini melibatkan 4 orang mahasiswa dan 1 tukang bangunan yang ahli di bidang pemasangan alat dan tentu saja tim P3M Poliban yang langsung terjun ke lapangan.

Kegiatan lapangan selalu diawasi dan diarahkan oleh tim Poliban agar dapat berjalan sesuai dengan rencana dan program yang telah digariskan. 


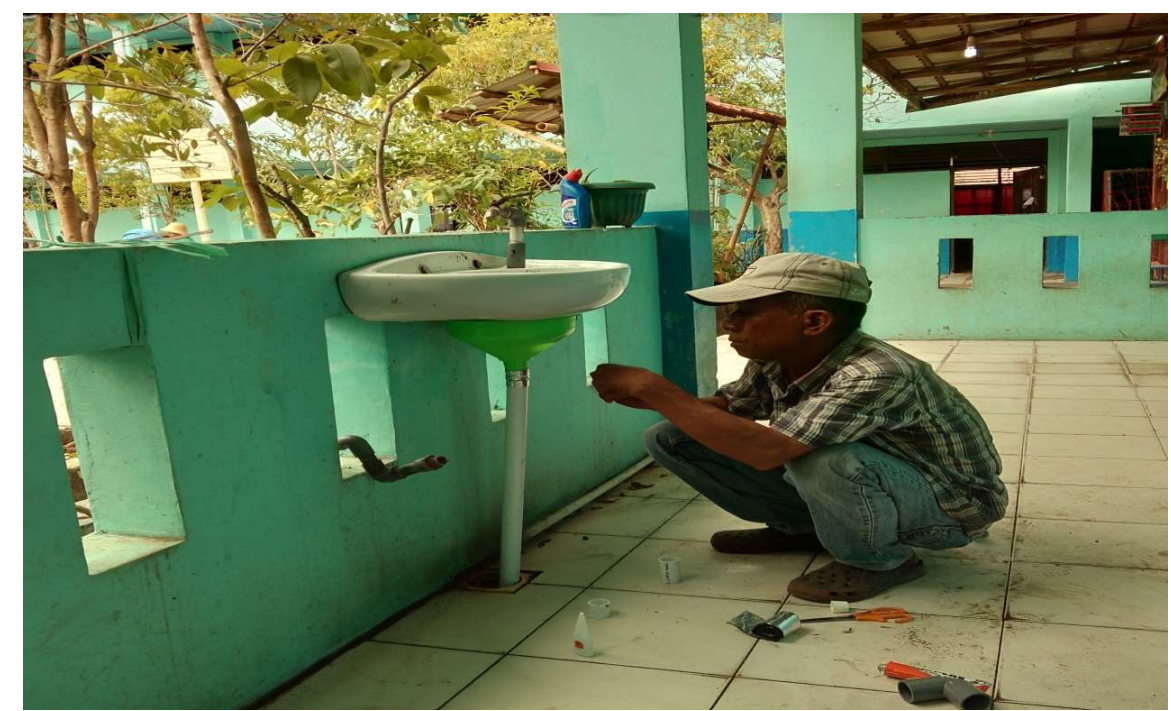

Gambar 4. Instalasi

Selain alat baru yang dipasang ada juga sebagian memperbaiki kondisi yang sudah ada semisal kebocoran dan tidak berfungsinya kran-kran air yang ada. Disini dibutuhkan kesabaran dan ketelitian dalam mengerjakan detail-detail alat dan bahannya.

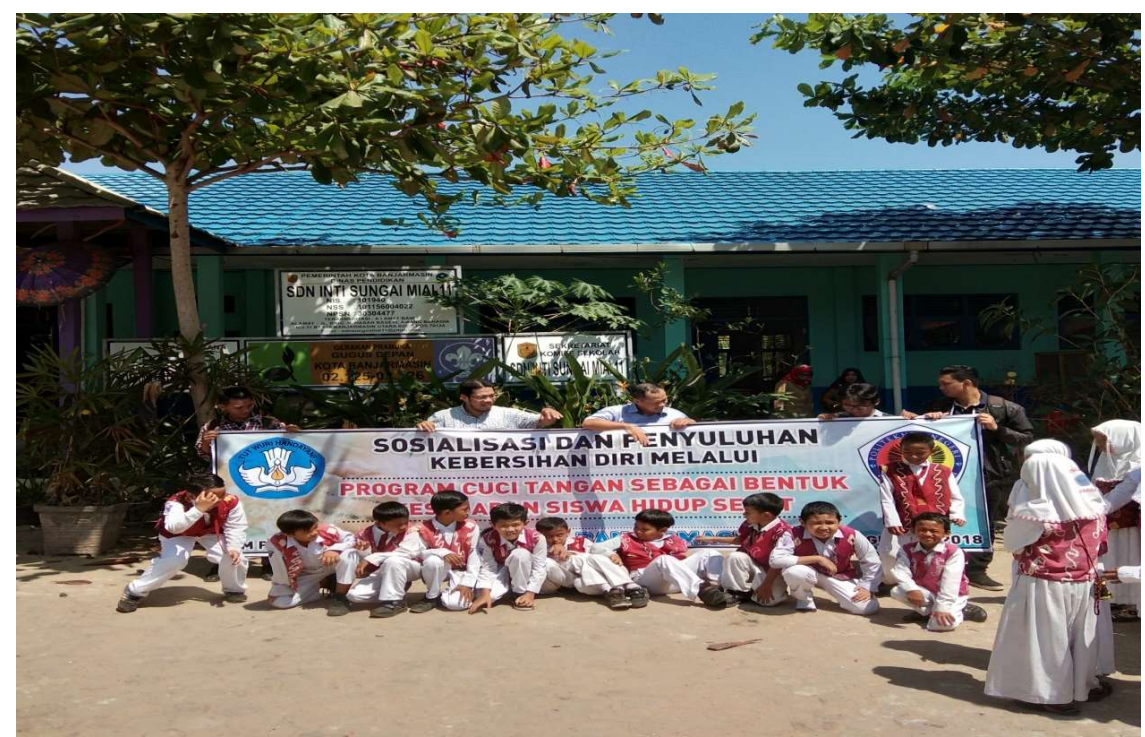

Gambar 5. Sosialisasi

Kegiatan sosialisasi, penyuluhan dan pembimbingan disaksikan langsung oleh siswa-siswa SDN 11 Inti Banjarmasin 


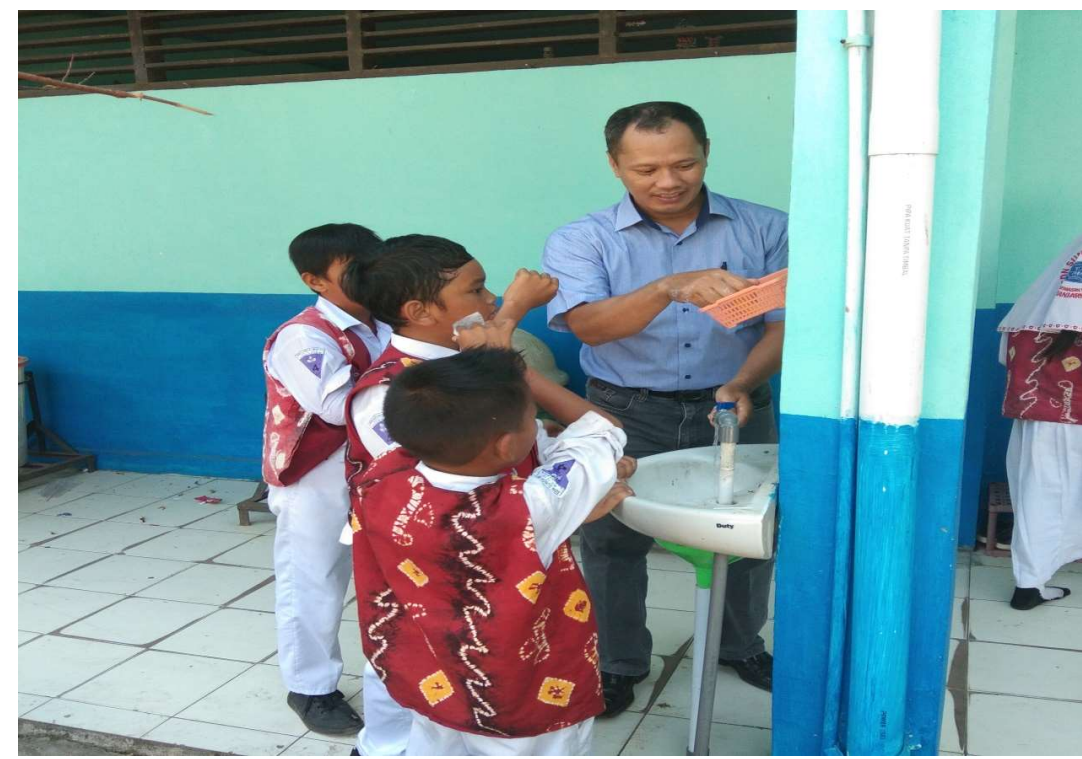

Gambar 6. Praktek

Praktek cuci tangan yang benar, bersih dan sehat serta hemat harus dicontohkan langsung agar siswa bertambah pengetahuan dan kesadarannya akan kebersihan diri dan kesehatan lingkungan sekolahnya.

\section{Tingkat ketercapaian sasaran program}

1. Penerapan gaya/cara hidup sehat siswa dapat menunjang prestasi akademik

2. Seluruh unsur sekolah mampu menjaga fasilitas dan menggunakannya dengan baik.

3. Tingkat kesehatan siswa meningkat

4. Sekolah sebagai pionir bagi lingkungan sekitar dalam hal kebersihan dan kesehatan.

\section{KESIMPULAN}

Berdasarkan hasil pemantauan dilapangan Personal hygiene (kebersihan diri) di lingkungan SDN 11 Inti Banjarmasin sudah masuk dalam aktegori cukup. Hal ini dibuktikan dengan sudah disediakannya sarana dan prasarana untuk kebersihan seperti tempat sampah, unit UKS dan kegiatan piket kebersihan tiap kelas serta guru wali ikut bertanggung jawab langsung. Namun demikian masih perlu dilakukan pembenahan dalam bidang kesehatan siswa yaitu belum maksimalnya fasilitas instalasi air bersih sebelum Tim P3M Poliban bekerjasama. Serta gaya hidup sehat dan bersih harus menjadi prioritas sekolah saat ini dan kedepannya.

Jadi perlu terus diberi pemahaman terhadap seluruh anggota sekolah agar tetap menjaga kebersihan lingkungan sekolah dan meningkatkan kebersihan individu secara rutin dan berkesinambungan (salah satunya cuci tangan) guna menciptakan 
lingkungan sekolah yang sehat agar kebiasaan yang bagus ini akan tertular ke lingkungan rumah dan masyarakat bagi anak didiknya.

\section{DAFTAR PUSTAKA}

DepkesRI. (2006). Profil Kesehatan Indonesia, 322.

Kamus Besar Bahasa Indonesia Pusat Bahasa Edisi Keempat. (2008) (4th ed.).Jakarta: PT. Gramedia Pustaka Utama.

Linda, T. (2004). Panduan Pencegahan Infeksi untuk Fasilitas Pelayanan Kesehatan dengan Sumber Daya Terbatas (1st ed.). Jakarta: Yayasan Bina Pustaka Sarwono Prawirohardjo.

World Health Organization (2008). Pencegahan dan Pengendalian Infeksi di fasilitas Pelayanan Kesehatan Pedoman Ringkas.

Tarwoto, M. (2010). Kebutuhan Dasar Manusia Dan Proses Keperawatan. Salemba Medika.

Siti Juariah, dkk. (2018). Pengenalan, Pemantauan dan Penyuluhan Pentingnya

Personal Higinies di SMAN X Pekanbaru, dari Akademi Analis Kesehatan

Pekanbaru, Jurnal Nasional E-ISSN 2614-7106 